\title{
Anatomical Features of Neural Foramen at T12-L1 Level for Endoscopic Transforaminal Approach of Paramedian and Foraminal Disc Herniations: An Anatomical Study on Fresh Human Cadavers
}

\author{
Halil CAN ${ }^{1}$, Cengiz GOMLEKSIZ², Furkan DIREN${ }^{3}$ Erdinc CIVELEK ${ }^{3}$, Atilla KIRCELLI ${ }^{4}$, Aydın AYDOSELI \\ Altay SENCER ${ }^{5}$
}

\begin{abstract}
${ }^{1}$ Biruni University, School of Medicine, Department of Neurosurgery and Private Medicine Hospital, Neurosurgery Clinic, Istanbul, Turkey 2Private Kolan International Hospital, Neurosurgery Clinic, Istanbul, Turkey ${ }^{3}$ Istanbul Gaziosmanpasa Taksim Training and Research Hospital, Department of Neurosurgery, Istanbul, Turkey

${ }^{4}$ Erasmus MC, Department of Neurosurgery, Rotterdam, Netherlands

${ }^{5}$ Istanbul University, Istanbul School of Medicine, Department of Neurosurgery, Istanbul, Turkey
\end{abstract}

Corresponding author: Halil CAN halilcandr1971@hotmail.com

\section{ABSTRACT}

AIM: To explore the anatomic features of the neural foramen in particularly at the T12-L1 level in order to assess reveal the safety and efficiency of the endoscopic transforaminal approach for paramedian and foraminal disc herniations at this level.

MATERIAL and METHODS: The study included 15 fresh human cadavers. The soft tissues were removed at the T12-L1 level and bony tissues, were exposed including the transverse processes. The bilateral facets and pars interarticulares at this level were resected revealing the foraminal anatomy and exiting roots. The anatomical structures constituting the triangular safe working zone (TSWZ) were explored. The nerve root length, nerve root width, nerve root angle, TSWZ height, and base of TSWZ base, nerve root width, nerve root angle and disc height were recorded.

RESULTS: The root length is the hypotenuse of the TSWZ between the axilla of the exiting root and the lateral margin of the pedicle, and the mean root length was $14.94 \pm 2.45 \mathrm{~mm}$. The dural height is the interval between the axilla of the exiting nerve root axilla and the superior end plate of the caudal vertebra, and the mean of the dural height was $10.95 \pm 1.74 \mathrm{~mm}$. The base of TSWZ is the distance between the lateral margin of the dural sac and the medial margin of the exiting root, and the mean measurement for the base measurement was $11.83 \pm 2.26 \mathrm{~mm}$.

CONCLUSION: According to the results data from our cadaveric study, we believe that Kambin's triangular working zone is a safe area to consider for the endoscopic transforaminal approach at the T12-L1 level, especially for paramedian and foraminal disc herniations.

KEYWORDS: T12-L1 level, Endoscopic transforaminal approach, Triangular safe working zone, Cadaver

ABBREVIATIONS: TSW: Triangular safe working zone.

Halil CAN OD: 0000-0002-5699-4089

Cengiz GOMLEKSIZ (10): 0000-0003-4789-5633

Furkan DIREN D : 0000-0001-6169-9722
Erdinc CIVELEK (1) : 0000-0002-3988-4064 Atilla KIRCELLI (D) : 0000-0003-2109-1274 Aydın AYDOSELI (1D) : 0000-0002-4695-8295
Altay SENCER (1D : 0000-0001-9925-5422 


\section{INTRODUCTION}

$\mathrm{M}$ inimally invasive approaches to access the spine have recently become more and more common especially in lumbar disc herniation cases. Kambin defined lumbar transforaminal discectomy via posterolateral approach in 1973 (6). The advances in technology since then made it possible to perform a full endoscopic transforaminal discectomy during the late 1980s, and endoscopic transforaminal approach gained widespread usage for the treatment of lumbar disc herniations in recent years. The triangular safe working zone (TSWZ) defined by Kambin is located between the superior vertebral plate of the caudal vertebra, dura, and exiting root (5). Determining the dimensions of the triangular working zone is crucial for a safe approach.

Minimally invasive approaches for thoracic discectomy have also been reported by many authors. Thoracic disc herniations are quite rare compared with lumbar herniations. In addition, discectomy in the thoracic spine is difficult and is prone to cause serious morbidity. Retracting the dural sac containing the spinal cord in thoracic spine is extremely dangerous and not recommended. This leads to more aggressive approaches like anterior thoracotomies and posterolateral costotransversectomies $(1,7)$. Therefore, the use of endoscopic posterolateral transforaminal approach seems to be a safe and straightforward method in this aspect. However, identification and exact knowledge of the dimensions of the safe working zone is much more important in the thoracic spine. Many authors have studied the morphometric data of TSWZ in the lumbar spine. But data is insufficient for the thoracic spine.

The aim of our study is to expose the foraminal anatomy of T12-L1 level through microdissection on fresh cadavers to provide the measurements of the TSWZ in T12-L1 level, along with the morphometric data associated with TSWZ, necessary for safe transforaminal approach.

\section{MATERIAL and METHODS}

This cadaver work was carried out with the permission certificate of the Turkish Republic Ministry of Justice, Forensic Medicine Institution (Decision number and date: B.03.1.ATK.0.01.00.08/74 and 07.February.2014). Fifteen fresh human cadavers with no history of previous spine surgery were studied. The mean age was 38.7 years (from 23 to 54) old, and specimens were consisting of seven females and eight males. Specimens with congenital or acquired anomalies were excluded from the study.

Cadavers were placed in prone position. The skinsubcutaneous tissue was passed through a median incision that corresponds to the T12-L1 level. The soft tissues were removed, and the bony tissues including transvers processes were exposed laterally. Facet joints together with pars interarticularis were resected bilaterally, revealing the foraminal anatomy and exiting roots. Every foramen was photographed with a marker for scaling and evaluated using a digital image analysis software (Image $\mathrm{J}$ ).

The anatomical structures constituting the TSWZ were studied. The nerve root length, TSWZ height, and base of TSWZ, nerve root width, nerve root angle, and disc height were measured (Figure 1).

\section{Statistical Analysis}

Statistical analysis was performed using the SPSS software (Version 21, Armonk, New York). The variables were investigated using visuals (histograms, probability plots) and analytical methods (Kolmogorov-Smirnov or Shapiro-Wilk test) to determine whether they are normally distributed or not. Descriptive analyses were presented using means and standard deviations for normally distributed variables. Paired Student's t-test was used to compare the measurements. A p-value of less than 0.05 was considered to show a statistically significant result.

\section{RESULTS}

A total of 30 T12-L1 intervertebral foramina were studied. The nerve root length, TSWZ height, and base of TSWZ, nerve root width, nerve root angle, and disc height measurements are listed in Table I.

Root length is the hypotenuse of the TSWZ between the axilla of the exiting root and the lateral margin of the pedicle. The mean root length was $14.94 \pm 2.45 \mathrm{~mm}$. Dural height is the interval between exiting nerve root axilla and the superior end plate of caudal vertebra. The mean of the dural height was $10.95 \pm 1.74 \mathrm{~mm}$. The base of TSWZ is the distance between the lateral margin of the dural sac and medial margin of the exiting root; the mean measurement for the base was 11.83 $\pm 2.26 \mathrm{~mm}$. The disc height is the distance between the end plates, and the mean height was $4.33 \pm 0.50 \mathrm{~mm}$. The mean nerve width was $3.88 \pm 0.47 \mathrm{~mm}$, and the mean angle of exiting root was $45.62 \pm 6.53$.

\section{DISCUSSION}

About $1 \%-2 \%$ of lumbar disc herniations are located in the

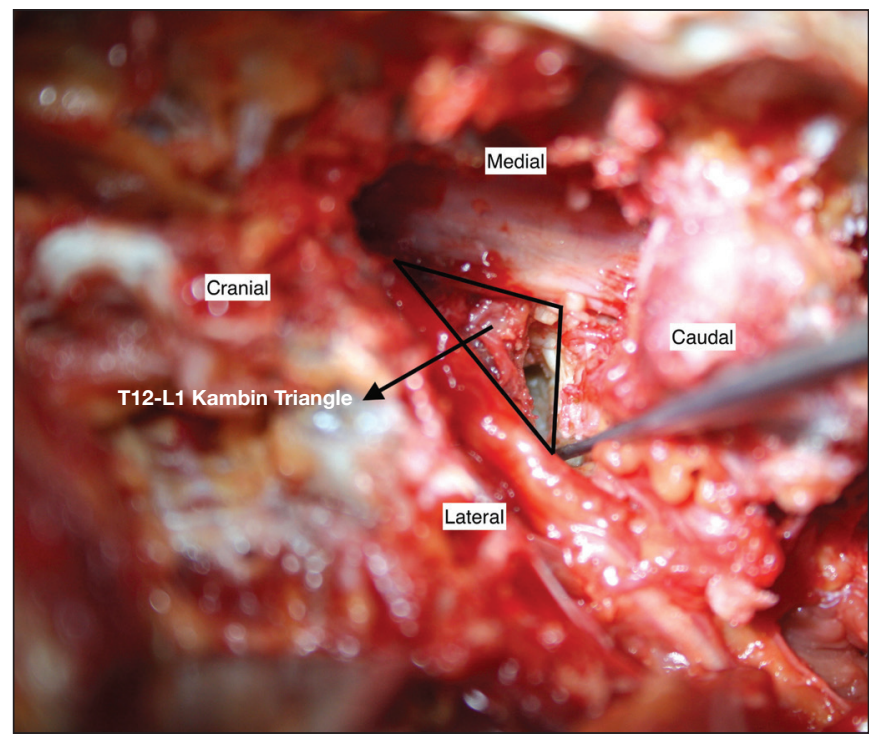

Figure 1: Borders of Kambin's triangle. 
Can H. et al: Endoscopic Transforaminal Approach at T12-L1

thoracolumbar junction $(4,14)$. Overall incidence is about one in every one million patients annually. The anterior, posterior, and posterolateral routes are usually used for surgical interventions especially for T12-L1 level. Anterior approaches require thoracotomy that may cause higher morbidity rates and postoperative patient discomfort or, at least, longer postoperative hospital stay. Posterolateral approaches, like costotransversectomy, also need extensive soft tissue dissection, which may lead to prolonged operative time, blood loss, and patient discomfort. Posterior approaches consist of

Table I: Measurements of the TSWZ

\begin{tabular}{|c|c|c|c|}
\hline & Mean \pm SD & Minimum & Maximum \\
\hline Root length right & $14.57 \pm 2.31 \mathrm{~mm}$ & $10.30 \mathrm{~mm}$ & $21.10 \mathrm{~mm}$ \\
\hline Root length left & $15.31 \pm 2.70 \mathrm{~mm}$ & $12.50 \mathrm{~mm}$ & $23.20 \mathrm{~mm}$ \\
\hline Root length mean & $14.94 \pm 2.45 \mathrm{~mm}$ & $11.40 \mathrm{~mm}$ & $22.15 \mathrm{~mm}$ \\
\hline Dural height right & $10.59 \pm 1.79 \mathrm{~mm}$ & $8.10 \mathrm{~mm}$ & $13.70 \mathrm{~mm}$ \\
\hline Dural height left & $11.32 \pm 1.83 \mathrm{~mm}$ & $8.90 \mathrm{~mm}$ & $15.10 \mathrm{~mm}$ \\
\hline Dural height mean & $0.95 \pm 1.74 \mathrm{~mm}$ & $8.50 \mathrm{~mm}$ & $14.25 \mathrm{~mm}$ \\
\hline Base of TSWZ right & $12.05 \pm 2.21 \mathrm{~mm}$ & $8.10 \mathrm{~mm}$ & $15.90 \mathrm{~mm}$ \\
\hline Base of TSWZ left & $11.60 \pm 2.37 \mathrm{~mm}$ & $7.90 \mathrm{~mm}$ & $15.30 \mathrm{~mm}$ \\
\hline Base of TSWZ mean & $11.83 \pm 2.26 \mathrm{~mm}$ & $8.00 \mathrm{~mm}$ & $15.30 \mathrm{~mm}$ \\
\hline Disc height right & $4.38 \pm 0.48 \mathrm{~mm}$ & $3.60 \mathrm{~mm}$ & $5.20 \mathrm{~mm}$ \\
\hline Disc height left & $4.27 \pm 0.54 \mathrm{~mm}$ & $3.50 \mathrm{~mm}$ & $5.50 \mathrm{~mm}$ \\
\hline Disc height mean & $4.33 \pm 0.50 \mathrm{~mm}$ & $3.65 \mathrm{~mm}$ & $5.35 \mathrm{~mm}$ \\
\hline Nerve width right & $3.92 \pm 0.41 \mathrm{~mm}$ & $2.90 \mathrm{~mm}$ & $4.50 \mathrm{~mm}$ \\
\hline Nerve width left & $3.84 \pm 0.57 \mathrm{~mm}$ & $2.80 \mathrm{~mm}$ & $4.60 \mathrm{~mm}$ \\
\hline Nerve width mean & $3.88 \pm 0.47 \mathrm{~mm}$ & $2.85 \mathrm{~mm}$ & $4.55 \mathrm{~mm}$ \\
\hline Nerve angle right & $46.14^{\circ} \pm 6.39^{\circ}$ & $36.50^{\circ}$ & $58.50^{\circ}$ \\
\hline Nerve angle left & $45.10^{\circ} \pm 7.18^{\circ}$ & $34.30^{\circ}$ & $57.20^{\circ}$ \\
\hline Nerve angle mean & $45.62^{\circ} \pm 6.53^{\circ}$ & $36.50^{\circ}$ & $57.15^{\circ}$ \\
\hline
\end{tabular}

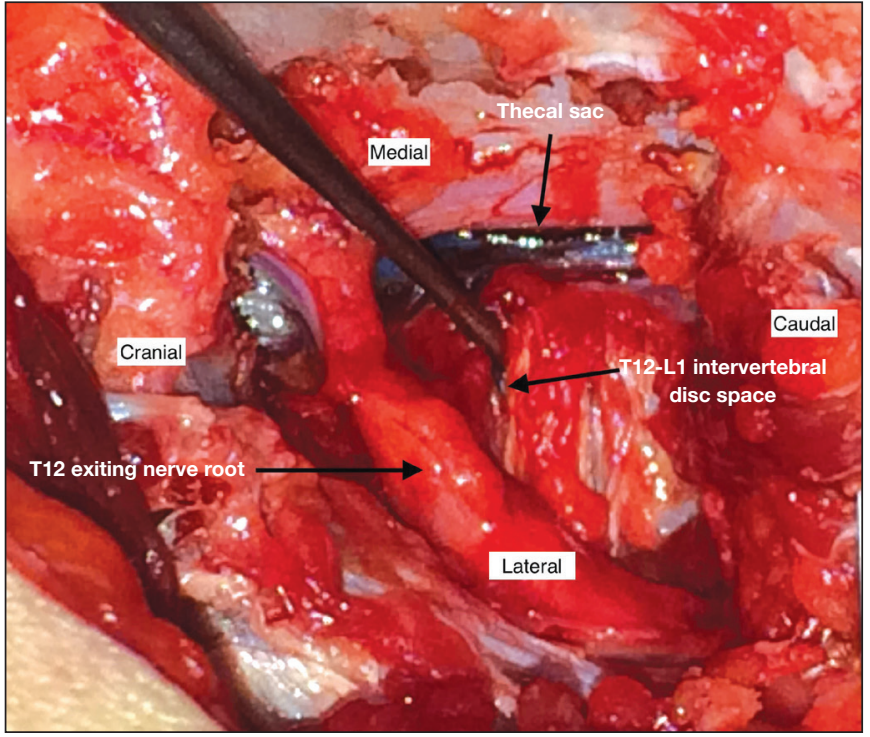

Figure 2: Elements of TSWZ.

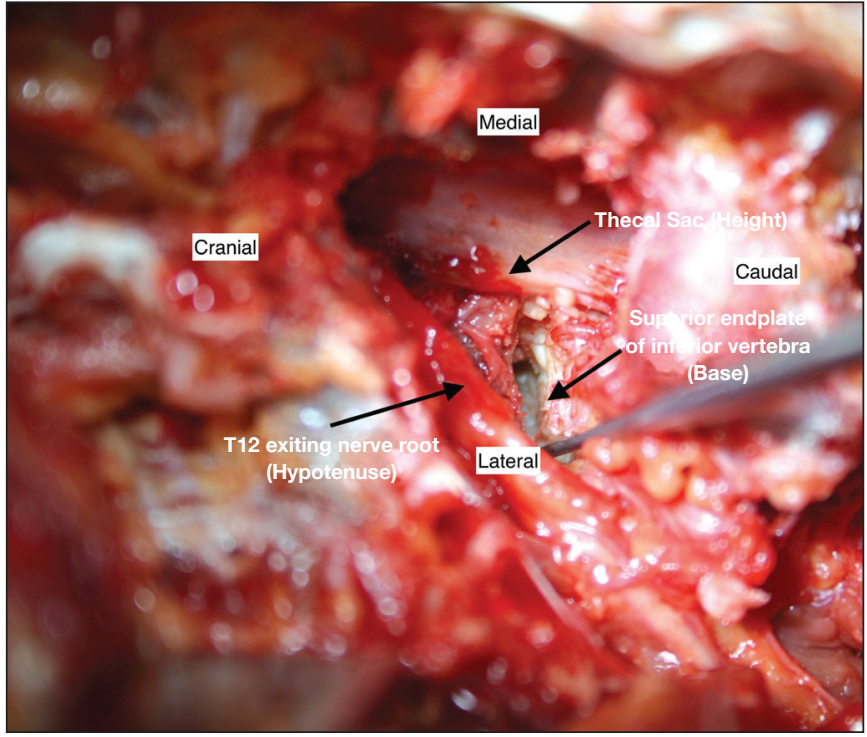

Figure 3: Anatomical structures of TSWZ. 
simple laminectomies with very little use and transpedicular route limited to paramedian and foraminal approaches.

Difficulties in thoracolumbar junction surgery, especially T12-L1 level, are related to the anatomical characteristics of this level, like the narrow space between the two pars interarticularis and proximity to medulla spinalis (13).

In 1983, Kambin and Gellman defined the triangle named after Kambin for safe and easy access through the intervertebral foramen to the disc space at the lumbar levels. Localized over the dorsolateral part of the intervertebral disc space, this triangular area forms a "safety working zone."The inferior vertebral plate of the disc space, lateral margin of the superior articular process of the inferior vertebrae and exiting root form the margins of this triangular safe zone (6). When adapted into a three-dimensional space, Mirkovic et al. defined the anatomical margins on coronary plane, and Min et al. on sagittal plane $(9,10)$.

The TSWZ at this level needs to be clearly defined in order to use the endoscopic transforaminal route for T12-L1 disc herniations. On their cadaver work, Mirkovic et al. found the mean measurements of the triangle for lumbar levels; the width is $18.9 \mathrm{~mm}$; height is $12.3 \mathrm{~mm}$; and the longer margin (hypotenuse) is $23 \mathrm{~mm}$ (10). Our measurements on 15 fresh cadavers for T12-L1 levels showed the mean lengths of width (base) as $11.83 \pm 2.26 \mathrm{~mm}$, (dural) height as $10.95 \pm 1.74 \mathrm{~mm}$, and hypotenuse (length of exiting root from the axilla to the lateral margin of pedicle) as $14.94 \pm 2.45 \mathrm{~mm}$.

The disc height, which is defined as the distance between the superior and inferior margins of the disc space lateral to the dural sac, was measured in the study of Lertudomphonwanit et al. on five cadavers (8). The mean length of disc height was found to be $5.83 \pm 1.04 \mathrm{~mm}$ at L1-2, $6.97 \pm 2.54 \mathrm{~mm}$ at L2-3, $9.3 \pm 1.24 \mathrm{~mm}$ at L3-4, $8.89 \pm 1.75 \mathrm{~mm}$ at L4-5, and $6.61 \pm 1.58 \mathrm{~mm}$ at L5-S1 levels. Mirkovic et al. made slightly different measurements for disc heights from L2-3 to L5-S1 levels, which were $5.2 \mathrm{~mm}, 6.3 \mathrm{~mm}, 5.9 \mathrm{~mm}$, and 4.8 $\mathrm{mm}$, consecutively (10). Suh et al. measured the mean disc height at T12-L1 level as $8 \mathrm{~mm}$ (12). But in our study, we found the mean value for disc height as $4.33 \pm 0.50$, which is considerably smaller than this.

Torun et al. reported the mean root diameter for L1, $3.3 \pm$ $0.4 \mathrm{~mm}$; L2, $3.5 \pm 0.4 \mathrm{~mm}$; L3, $3.9 \pm 0.4 \mathrm{~mm}$; L4, $3.9 \pm 0.5$ $\mathrm{mm}$; and L5, $3.9 \pm 0.4 \mathrm{~mm}$, in their study with 15 cadavers (15). Our study showed that the mean diameter of the exiting T12 nerve root at T12-L1 level was $3.88 \pm 0.47 \mathrm{~mm}$. Exiting angles of these roots forming the longer border of the triangle (hypotenuse) were measured by Attar et al. These are the following measurements: L1, $35.2 \pm 1.7$; L2, $36.4 \pm 1.9$; L3, $37.8 \pm 2.4$; L4, $39.3 \pm 2.3$; and L5, $39.3 \pm 2.6$ degrees (2). Another study on the radiological analysis of the triangular working zone by Civelek et al. found the exiting root angles on the coronary plane for the right $L 3,37.41 \pm 7.12$; left $L 3$, $35.46 \pm 7.98$; right L4, $39.20 \pm 8.63$; and left L4, $42.51 \pm 13.14$ degrees (3). In our study, the mean exiting root angle was $45.62 \pm 6.53$ degrees.
In their clinical study of three patients, Telfeian et al. described an endoscopic transforaminal approach for T12-L1 discs with successful results (13). They accessed the disc space from an entry point $5-8 \mathrm{~cm}$ lateral to the midline, through the Kambin's triangle between the exiting and traversing nerve roots. Neither of their patients had midline herniations. No complications like nerve root injury, dural tears, infections or thrombophlebitis, spinal instability, and renal, vascular or pulmonary injury were noted. They just had consideration for three important points before the operation-the proximity of the kidney, proximity of the rib, and ratio of dural sac diameter to the spinal canal diameter. They recommended that the needle has to enter through the disc space at the mid-pedicle line to avoid the thecal sac. They concluded that for T12L1 foraminal or paramedian disc herniations, endoscopic transforaminal approach was successful and safe, eliminating the need for thecal sac retraction, facet resection, and thus any future stabilization process. In our study, we observed that in all 15 cadavers, the traversing $\mathrm{L} 1$ nerve root was leaving the dura distal the disc space. So, we also believe that for transforaminal access to T12-L1 level, the thecal sac and exiting root are the major neural structures to consider.

Straus et al. examined the lateral access to the thoracolumbar junction (T10-11, T11-12, T12-L1, L1-2, and L2-3) on six cadavers and operated three patients (11). They examined the body cavity, deep muscle structure, and access points of the cadavers. They reported that using the lateral approach, they could reach the T12-L1 level, which is a transitional region, through the retroperitoneal route, retropleural route, or both. For T12-L1 level, the authors used the T11-12 intercostal space. Rib resection was not necessary unless for autograft material. The psoas muscle was inconsistently encountered, but the fibers of the diaphragmatic crus were commonly encountered. Usually, it was sufficient to spread fibers with tubular dilators and retractors to reach the disc space. The authors did not recommend chest tube insertion even if the parietal pleura was violated. Additionally, we did not encounter any fibers of the diaphragm or ribs obstructing access to the T12-L1 level in our study.

\section{CONCLUSION}

Considering the data from our cadaveric study, we believe that Kambin's triangular working zone is a safe area for endoscopic transforaminal approach to T12-L1 level, especially for paramedian and foraminal herniations, as long as the thecal sac and medulla are avoided through a more posterolateral route. Moreover, this triangle provides a safe and quite minimal invasive access when performing microdiscectomies, avoiding bone resection. More research is necessary for minimally resection of median, calcified herniations.

\section{- REFERENCES}

1. Aizawa T, Sato T, Sasaki H, Matsumoto F, Morozumi N, Kusakabe T, Itoi E, Kokubun S: Results of surgical treatment for thoracic myelopathy: Minimum 2-year follow-up study in 132 patients. J Neurosurg Spine 7:13-20, 2007 
Can H. et al: Endoscopic Transforaminal Approach at T12-L1

2. Attar A, Ugur HC, Uz A, Tekdemir I, Egemen N, Genc Y: Lumbar pedicle: Surgical anatomic evaluation and relationships. Eur Spine J 10:10-15, 2001

3. Civelek E, Solmaz I, Cansever T, Onal B, Kabatas S, Bolukbasi N, Sirin S, Kahraman S: Radiological analysis of the triangular working zone during transforaminal endoscopic lumbar discectomy. Asian Spine J 6:98, 2012

4. Hsu K, Zucherman J, Shea W, Kaiser J, White A, Schofferman J, Amelon C: High lumbar disc degeneration. Incidence and etiology. Spine 15:679-682, 1990

5. Kambin P, Brager M: Percutaneous posterolateral discectomy. Anatomy and mechanism. Clin Orthop Relat Res 223:145154, 1987

6. Kambin P, Gellman H: Percutaneous lateral discectomy of the lumbar spine a preliminary report. Clin Orthop Relat Res 174:127-132, 1983

7. Le Roux PD, Haglund MM, Harris AB: Thoracic disc disease: Experience with the transpedicular approach in twenty consecutive patients. Neurosurgery 33:58-66, 1993

8. Lertudomphonwanit T, Keorochana G, Kraiwattanapong C, Chanplakorn P, Leelapattana P, Wajanavisit W: Anatomic considerations of intervertebral disc perspective in lumbar posterolateral approach via Kambin's triangle: Cadaveric study. Asian Spine J 10:821, 2016
9. Min JH, Kang SH, Lee JB, Cho TH, Suh JK, Rhyu IJ: Morphometric analysis of the working zone for endoscopic lumbar discectomy. Clin Spine Surg 18:132-135, 2005

10. Mirkovic SR, Schwartz DG, Glazier KD: Anatomic considerations in lumbar posterolateral percutaneous procedures. Spine 20:1965-1971, 1995

11. Straus D, Takagi I, O’Toole J: Minimally invasive direct lateral approach to the thoracolumbar junction: Cadaveric analysis and case illustrations. J Neurosurg Part A: Cent Eur Neurosurg 76:56-62, 2015

12. Suh S, Shingade VU, Lee S, Bae J, Park C, Song J: Origin of lumbar spinal roots and their relationship to intervertebral discs: A cadaver and radiological study. J Bone Joint Surg $\mathrm{Br}$ 87:518-522, 2005

13. Telfeian AE, Jasper GP, Oyelese AA, Gokaslan ZL: Technical considerations in transforaminal endoscopic spine surgery at the thoracolumbar junction: Report of 3 cases. Neurosurg Focus 40:E9, 2016

14. Tokuhashi $\mathrm{Y}$, Matsuzaki H, Uematsu $\mathrm{Y}$, Oda H: Symptoms of thoracolumbar junction disc herniation. Spine 26:E512-E518, 2001

15. Torun $F$, Dolgun $H$, Tuna $H$, Attar $A$, Uz A, Erdem $A$ : Morphometric analysis of the roots and neural foramina of the lumbar vertebrae. Surg Neurol 66:148-151, 2006 